\title{
The Anodic Behaviour of Oxide Ion at Glassy Carbon Electrode in LiF-KF Eutectic Melt
}

\author{
Yasuhiko ITO*, Toshihide TAKEnAKA*, Keiko EMA* and Jun OISHI*
}

\begin{abstract}
The anodic behaviour of the oxide ion at glassy carbon electrode in LiF-KF euctectic melt was investigated by the chronopotentiometry, potential sweep method and the potential step method, together with IR spectroscopy and gas chromatography. The potential sweep method was the most suitable for monitoring the oxide ion concentration in the melt and estimating the value of the diffusion coefficient of the oxide ion in the melt. The diffusion coefficient of the oxide ion in the melt was estimated to be $5 \times 10^{-5} \mathrm{~cm}^{2} / \mathrm{sec}$ at $550^{\circ} \mathrm{C}$. The reaction rate constant, $k_{\mathrm{f}}$, of the irreversible anodic oxidation of oxide ion in the melt and the roughness factor of the glassy carbon electrode were estimated to be about $10^{-2} \mathrm{~cm} / \mathrm{s}$ and 7 , respectively. The oxide ion contamination level of a melt, that was vacuum dried before melting and was contained in a high purity alumina cruicible, was estimated to be about $250 \mathrm{ppm}$ ( $\mathrm{F}^{-}$basis). The possibility of electrolytic purification of the melt was also suggested. The results obtained should be also useful when considering the consumption of graphite mederator in the MSBR.
\end{abstract}

\section{Introduction}

Molten fluoride is a useful meterial for use in many future energy processes, such as the Molten Salt Breeder Reactor, heat storage systems, etc. To us this melt for such purposes, it is necessary to monitor the concentration of oxide ion in the melt and to control it to a desirable level, because the oxide ion concentration strongly influences corrosion of the container material and the precipitation characteristics of dissolved species, which in turn largely determine plant lifetime and process efficiency. In order to monitor and control the oxide ion concentration level, electrochemical methods might play an important role, and in this sense, the anodic behaviour of oxide ion in fluoride melt becomes an important subject. From this viewpoint, Manning and Mamantov $^{1)}$ have studied the electrochemical behaviour of oxide ion in several molten fluorides and described that the anodic reaction of oxide ion at glassy carbon electrodes does not give reproducible results. It is, however, still interesting to know the details of the anodic behaviour of oxide ion at glassy carbon electrodes. That is, if the glassy carbon elec-

* Department of Nuclear Engineering, Faculty of Engineering Kyoto University (Sakyo-ku, Kyoto 606)

Key Words: Molten Salt, Breeder Reactor, Molten Fluoride, Oxide Ion, Anodic Behaviour trode shows reproducible electrochemical behaviour, it can be used as an oxide ion concentration indicator. In addition, if it works well, it can be used for the purpose of the electrochemical elimination of oxide ion from the fluoride melt, and in this case, electrolytic products are only gases and the contamination of metallic ion or other species will be minimized.

From a different viewpoint, concerning the Molten Salt Breeder Reactor, the behaviour of the glassy carbon electrode would supply basic informations about the consumption of graphite moderator.

In this paper, $\mathrm{LiF}-\mathrm{KF}$ eutectic melt has been selected as an example of a fluoride melt, and detailed studies have been carried out on the anodic behaviour of oxide ion at glassy carbon electrode in this melt, using several conventional electrochemical methods, as well as IR spectroscopy and gas chromatographic analysis of the evolved anode gas.

\section{Experimental Method and Apparatus}

Commercial LiF and KF (Reagent Grade, Wako Chemicals Co., Ltd.) were mixed and the eutectic mixture was vacuum dried for over two nights at $200^{\circ} \mathrm{C}$, after which it was then melted in a high purity alumina crucible (Nippon Kagaku Togyo Co. Ltd., SSA-S) under 
an argon (water content $<10 \mathrm{ppm}$ ) atmosphere at $550^{\circ} \mathrm{C}$. This procedure is not a rigorous one to prepare oxide-free fluoride melt, because residual oxide ion cannot be removed unless the melt is fused under, for example, $\mathrm{H}_{2}-\mathrm{HF}$ gas mixture ${ }^{2}$. Also, the alumina crucible may introduce some oxide ion into the melt. But in our case, this insufficiency is not a serious problem because, as mentioned later, one of the purposes of the experiments was to estimate the oxide ion contamination level resulting from this kind of insufficient experimental condition.

The oxide ion concentration in the melt was controlled by adding the appropriate amount of dry, $\mathrm{CO}_{2}$-free $\mathrm{Li}_{2} \mathrm{O}$ (supplied by Prof. K. Niki, Yokohama National University). For the IR spectrum and gas chromatographic analysis of the evolved anode gas, the electrolytic cell and sampling line were arranged as shown in Fig. 1. A $5 \mathrm{~mm}$ diameter glassy carbon rod (Touhoku Kyowa Carbon Co. Ltd.) was used as the working electrode. Liquid tin was used as the counter electrode to absorb deposited alkali metal ( $\mathrm{Li}$ and $\mathrm{K}$ ) as an alloy. Molybdenum wire was used as the lead for the liquid tin cathode. Solid Al-Alkali-metal alloy was used as a quasi-reference electrode. This electrode maintains a potential of about $0.1 \mathrm{~V} v s$. the alkali-metal deposition potential in the same melt, although there is still some thermodynamic uncertainty in the precise value of this potential.

Evolved anode gas was trapped in the gas sampler in a conventional manner.

A similar cell shown in Fig. 2, was used for electrochemical analysis. In this case, however, an aluminum plate, having an area of 10

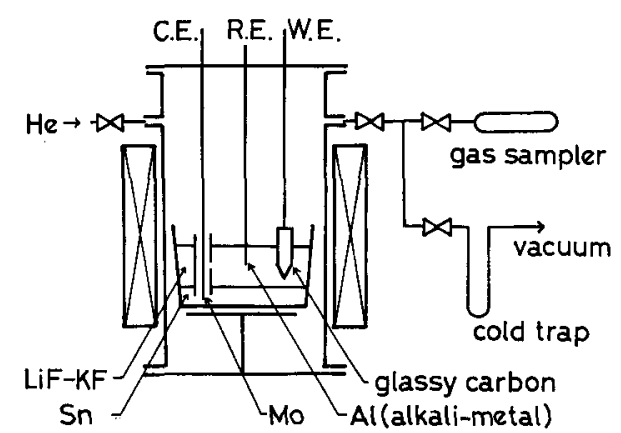

Fig. 1 Electrolytic cell and gas sampling line

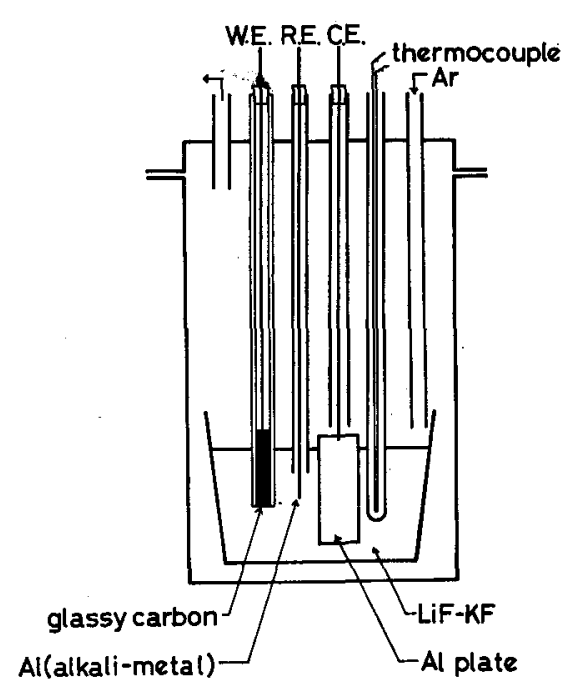

Fig. 2 Cell for electrochemical analysis

$\mathrm{cm}^{2}$ and a width much greater than that of the working electrode, was used as the alkalimetal-absorbing counter electrode in order to minimize the effects of convection. The vertical surface of the glassy carbon rod was covered with a high purity alumina pipe, (Nippon Kagaku Togyo Co. Ltd., SSA-S), in order to limit the active area only to the bottom of the rod. Penetration of the melt into the electrodepipe interface was not observed after the experiments.

All experiments were carried out at $550^{\circ} \mathrm{C}$.

\section{Results and Discussion}

\subsection{Chronopotentiometry}

Figure 3 shows an example of the experimental results obtained by chronopotentiometry. The chronopotentiogram is not so simple due to the discharge of fluoride ion on the carbon surface, which may form several types of surface compounds. Similar tendency was reported by Lantelme, Damianacos and Chemla ${ }^{3)}$, for the anodic reaction in cryolite melt. At least, however, first plateau in the figure might be attributed to the discharge of oxide ion. To confirm this, potentiostatic electrolysis was carried out and evolved anode gas was analysed qualitatively.

The electrode potential was kept at $3.0 \mathrm{~V} v s$. the quasi-reference electrode, which corresponds to the potential region of the first pleateau in 


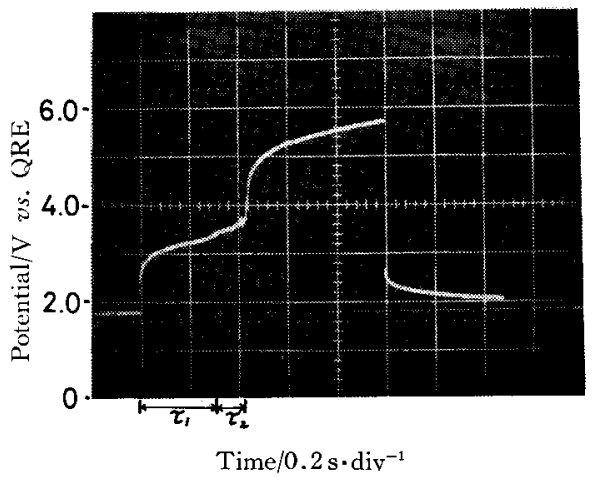

Fig. 3 Typical chronopotentiogram $\left[\mathrm{O}^{2-}\right]_{\text {adcied }}: 0.3 \mathrm{~mol} \%\left(\mathrm{~F}^{-}\right.$basis $), i_{0}: 80 \mathrm{~mA}$

the chronopotentiogram. In the IR spectrum, absorbance due to $\mathrm{CO}$ and $\mathrm{CO}_{2}$ was clearly observed and that due to $\mathrm{COF}_{2}$ or $\mathrm{CF}_{4}$ is not observed at all. The presence of large amount of oxygen in the evolved gas was confirmed by gaschromatography.

This fact might suggest that, at least in the potential region of the first plateau, oxide ion discharge reaction is the predominant one.

\subsection{Potential sweep method}

Figure 4 shows a sample voltammogram obtained by the potential sweep method.

A clear current peak is observed in the figure, although current fluctuation is observed at the potential around $3.6 \mathrm{~V}$ vs. the quasi-reference electrode.

The potential of $3.6 \mathrm{~V}$ at which perturbation is observed in Fig. 4 corresponds to the potential at which potential fluctuation is observed in Fig. 3. Addition of the peroxide ion into the melt increases the current of the first peak, but does not show new peak. Thus, this current increase can not be attributed to a direct

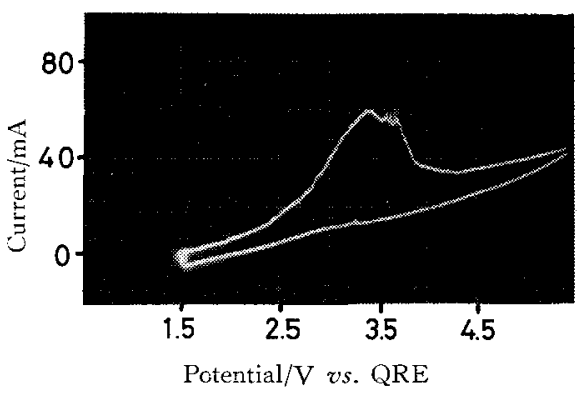

Fig. 4 Typical potential sweep curve $\left[\mathrm{O}^{2-}\right]_{\text {added }}: 0.15 \mathrm{~mol} \%\left(\mathrm{~F}^{-}\right.$basis), scan rate $: 2.0 \mathrm{~V} / \mathrm{s}$ electrochemical discharge of peroxide ion, but might be attributed to a discharge of the oxide ion which is produced by, for example, disproportionation reaction,

$$
\mathrm{O}_{2}{ }^{2-}=\mathrm{O}^{2-}+1 / 2 \mathrm{O}_{2} \text {. }
$$

That is, peak current of the first peak might be analysed by considering only a discharge of the oxide ion in the melt. An irreversible reaction is suggested by the fact that no peak current is observed during the reverse scan. These observations might be attributed to the diffusion controlled irreversible anodic reaction of the oxide ion in the melt. As expected, in accordance with Nicholson's well known equation $^{4}$ for an irreversible diffusion controlled reaction:

$$
\left.\begin{array}{l}
i=n F A C_{0} \sqrt{\pi D_{0} b} \chi(b t) \\
b=\alpha n_{\mathrm{a}} F v / R T
\end{array}\right\}
$$

the peak current changes linearly with the added amount of oxide ion in the melt at constant scan rate as shown in Fig. 5, and with the square root of the scan rate at constant oxide ion concentration as shown in Fig. 6. Here, $v$ denotes the potential scan rate; $t$, the time from the beginning of the scanning; $\alpha$, the transfer coefficient of the charge transfer step; $n$, the number of electrons transfered during the rate determining step; and $A$ the electrode area. The other symbols in the equation have their conventional meanings. $\chi$ is the special function which has been evaluated numerically by Nicholson and Shain ${ }^{4}$.

Concerning Fig. 5, it is noteworthy that each

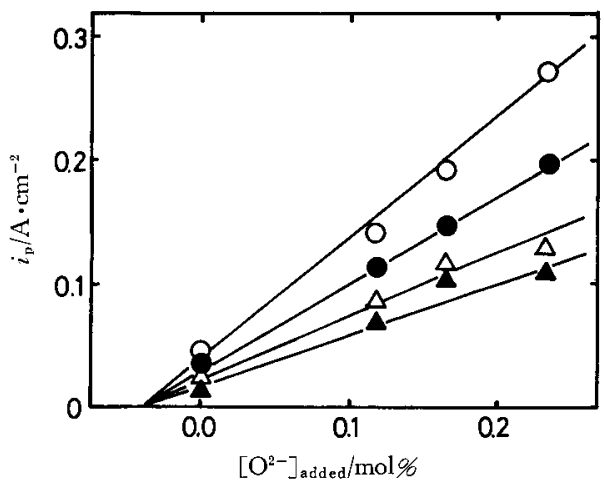

Fig. 5 Relation between peak current and $\left[\mathrm{O}^{2-}\right]_{\text {added }}$ at various scan rates scan rate $: 0 ; 1.0 \mathrm{~V} / \mathrm{s}, 0 ; 0.5 \mathrm{~V} / \mathrm{s}, \Delta ; 0.2 \mathrm{~V} / \mathrm{s}$, $\Delta ; 0.1 \mathrm{~V} / \mathrm{s}$ 


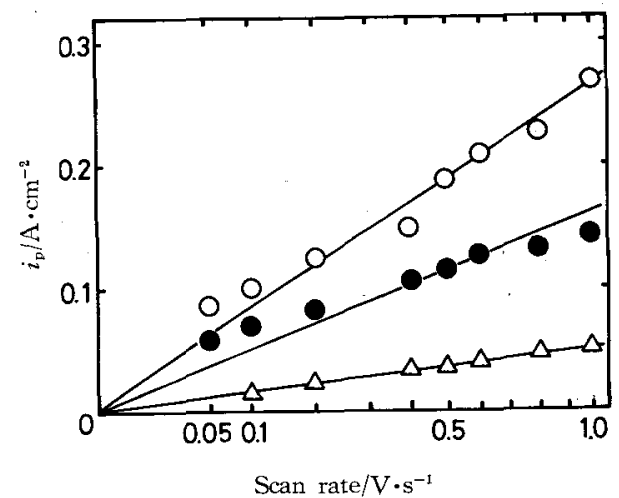

Fig. 6 Relation between peak current and square root of scan rate at various oxide ion concentrations $\left[\mathrm{O}^{2-}\right]_{\text {added }}: 0 ; 0.230 \mathrm{~mol} \%\left(\mathrm{~F}^{-}\right.$basis $)$, basis), $\triangle ; 0.0 \mathrm{~mol} \%$ ( $\mathrm{F}^{-}$basis)

straight line intersects the $\mathrm{x}$-axis at the same concentration, $-0.025 \mathrm{~mol} \%$, of $\mathrm{O}^{2-}$ added. This means that before adding $\mathrm{Li}_{2} \mathrm{O}$ into the melt, $0.025 \mathrm{~mol} \% \mathrm{O}^{2-}$ was already present in the melt as a contaminant. The oxide ion concentration level of the $\mathrm{LiF}-\mathrm{KF}$ eutectic melt that was prepared according to the method described in section 2 is, then, estimated to be around $250 \mathrm{ppm}$ ( $\mathrm{F}^{-}$basis).

The diffusion coefficient of the oxide ion also can be estimated from these experiments.

If we assume $\alpha n_{\mathrm{a}}=1$, the diffusion coefficient of the oxide ion in the melt is calculated to be $5 \times 10^{-5} \mathrm{~cm}^{2} / \mathrm{s}$ by applying equation (1) and using many other data obtained under different conditions*'.

\subsection{Potential step method}

As discussed above, it has been concluded that the anodic oxidation of oxide ion at glassy carbon electrode in $\mathrm{LiF}-\mathrm{KF}$ eutectic melt is a diffusion controlled irreversible process.

In this section, the rate constant of this

*1 The assumption that $\alpha n_{\mathrm{a}}=1$ has not a rigorous theoretical basis, but it seems reasonable to consider this value to stay around 1 (eg. $\alpha=0.5, n_{\mathrm{a}}=2$ ). So, as a representative value, the value of 1 has been chosen for this estimate. This assumption yields reasonable values for the diffusion coefficient, so that at least the order of magnitude of the diffusion coefficient can be considered to be reliable.

To make the situation clearer, exact values of the diffusion coefficient should be determined by other methods, after which the value of $\alpha n_{\mathrm{a}}$ can then be obtained. This is the subject of a future report. irreversible reaction is estimated by the potential step method. Figure 7 shows an example of the transition curve obtained by the potential step method. According to the theory ${ }^{5)}$, the relation between the current $i$ and the rate constant $k_{\mathrm{f}}$, the concentration $C$, the diffusion coefficient $D$ and the electrode area $A$ is expressed as follows :

$$
i=n F A k_{\mathrm{f}} C\left(1-2 k_{\mathrm{f}} t^{1 / 2} / \pi^{1 / 2} D^{1 / 2}\right)
$$

under the assumption that $\left(k_{\mathrm{f}} / D^{1 / 2}\right) t^{1 / 2} \ll 1$. If the electrode roughness factor $\beta$ is incorporated into equation (2), it becomes:

$$
i=n F \beta A k_{\mathrm{f}} C\left(1-2 k_{\mathrm{f}} t^{1 / 2} / \pi^{1 / 2} D^{1 / 2}\right)
$$

As is seen in Fig. 8, a linear relation between current and the square root of time is

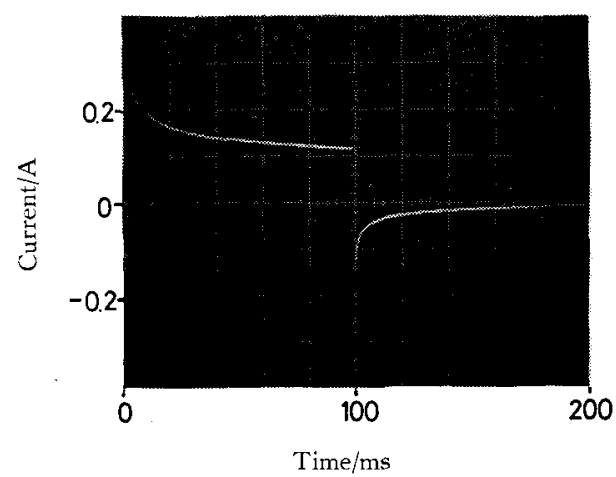

Fig. 7 Typical potential step curve

$\left[\mathrm{O}^{2-}\right]: 0.2 \mathrm{~mol}, \mathrm{~g}^{-}$( $\mathrm{F}^{-}$basis), potential was stepped from rest potential to $3.0 \mathrm{~V}$ (vs. alkali-metal deposition potential) at time 0 , and from $3.0 \mathrm{~V}$ (vs. alkalimetal deposition potential) to rest potential at time $100 \mathrm{~ms}$

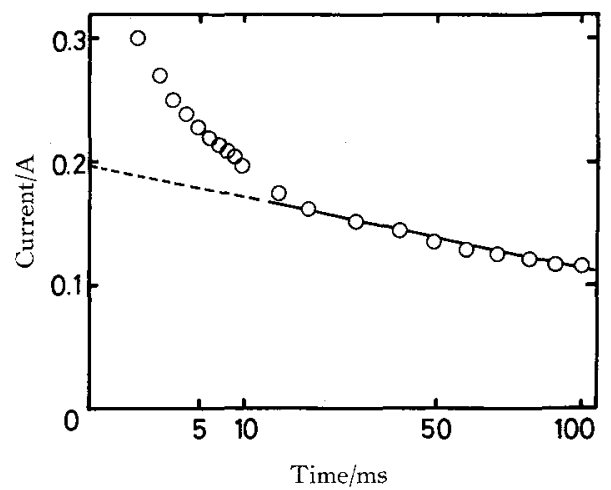

Fig. 8 Relation between current and square root of time

$\left[\mathrm{O}^{2-}\right]: 0.2 \mathrm{~mol} \%$ (F- basis), potential was stepped from rest potential to $3.0 \mathrm{~V}$ (vs. alkali-metal deposition potential) 


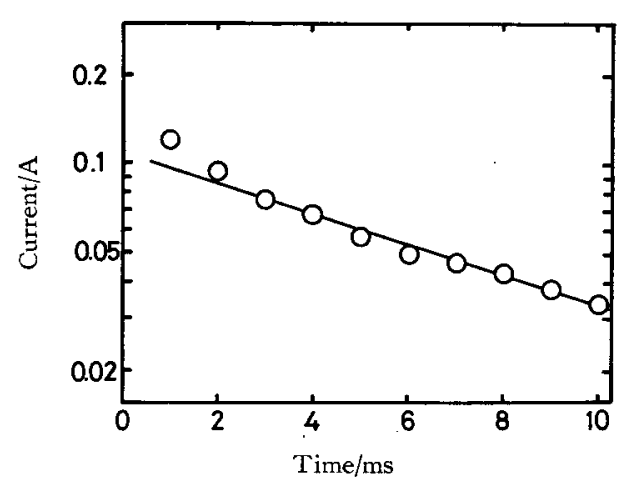

Fig. 9 Relation between logarithm of current deviation and time (initial current decrease in Fig. 8)

observed over the range $10 \sim 100 \mathrm{~ms}$.

By substituting a diffusion coefficient value of $5 \times 10^{-5} \mathrm{~cm}^{2} / \mathrm{s}$ and a concentration of $C=0.2$ mol\% (which was measured by a separate potential sweep experiment) into equation (3), the values of $\beta$ and $k_{\mathrm{f}}$ are estimated from this straight line to be 7 and $7.0 \times 10^{-3} \mathrm{~cm} / \mathrm{s}$ respectively.

The sharp current decrease over the time range of $0 \sim 10 \mathrm{~ms}$ in Fig. 8 might be attributed to the double layer electrode capacity. This is confirmed by the linear relation between the logarithm of the current deviation (from the straight line) and time, as seen in Fig. 9. From tne slope of the line in Fig. 9 and the value of 7 for the roughness factor, the double layer capacity is calculated to be $400 \mu \mathrm{F} / \mathrm{cm}^{2}$, which seems several times higher compared with many other double layer capacity data ${ }^{6}$.

\section{Conclusions}

The anodic behaviour of the oxide ion at glassy carbon electrode in $\mathrm{LiF}-\mathrm{KF}$ eutectic melt was investigated by the chronopotentiometry, potential sweep method and the potential step method, together with IR spectroscopy and gas chromatography. Among the electrochemical methods, the potential sweep method was the most reliable for monitoring the oxide ion concentration in the melt and for estimating the value of the diffusion coefficient of the oxide ion in the melt. The diffusion coefficient of the oxide ion in the malt was estimated to be $5 \times 10^{-5} \mathrm{~cm}^{2} / \mathrm{s}$ at $550^{\circ} \mathrm{C}$.

The possibility of electrolytic purification of the melt was also suggested. The reaction rate constant, $k_{\mathrm{f}}$, of the irreversible anodic oxidation of oxide ion in the melt and the roughness factor of the glassy carbon electrode were estimated to be about $10^{-2} \mathrm{~cm} / \mathrm{s}$ and 7 , respectively.

The oxide ion contamination level of a melt, that was vacuum dried before melting and was contained in a high purity alumina crucible, was estimated to be about $250 \mathrm{ppm}\left(\mathrm{F}^{-}\right.$basis).

\section{References :}

1) D.L. Manning and G. Mamantov, J. Electrochem. Soc. 124, 480 (1977).

2) A.L. Mathews and C.F. Baes, Jr., Inorg. Chem. 7, 373 (1968).

C.E. Bamberger, "Abvances in Molten Salt Chemistry", Vol. 3, p. 182 (1975).

3) F. Lantleme, D. Damianacos and M. Chemla, $J$. Electrochem. Soc. 127, 498 (1980).

4) R.S. Nicholson and I. Shain, Anal. Chem. 36, 706 (1964).

5) D.D. MacDonald, "Transient Techniques in Electrochemistry," p. 77, Plenum Press (1977).

6) E.A. Ukshe and N.G. Bukun, J. Electroanal. Chem. 32, 283 (1971).

(Received Jun. 30, 1983; Accepted Sep. 10, 1983) 